\title{
Factors Associated with Medication Adherence in Patients with Chronic Obstructive Pulmonary Disease
}

\author{
Tamas Agh Andras Inotai Agnes Meszaros \\ University Pharmacy Department of Pharmacy Administration, Semmelweis University, Budapest, Hungary
}

\section{Key Words}

Chronic obstructive pulmonary disease $\cdot$ Medication

adherence $\cdot$ Respiratory therapy $\cdot$ Quality of life

\begin{abstract}
Background: Predictors of medication adherence are not well known in chronic obstructive pulmonary disease (COPD). It is therefore necessary to identify factors associated with adherence to improve the effectiveness of COPD management within real-world situations. Objectives: The goals of this study were to estimate adherence to respiratory medication and to identify factors related to adherence in COPD patients. Methods: This was an observational, crosssectional study conducted on a sample of COPD outpatients. The following information was obtained: adherence to respiratory therapy (Morisky Medication Adherence Scale), age, gender, smoking status, COPD severity [Global Initiative for Chronic Obstructive Lung Disease (GOLD) stage], lung function [post-bronchodilator forced expiratory volume in $1 \mathrm{~s}$ $\left.\left(\mathrm{FEV}_{1}\right)\right]$, treatment regimen for COPD, COPD medication costs per month paid by the patient and health-related quality of life (EuroQol 5-dimension questionnaire). A multivariate logistic regression analysis was performed to identify the independent predictors of adherence. Results: Of the 170 participants (mean age 63.8 years, $41.8 \%$ male), $58.2 \%$ reported optimal adherence. Adherence to respiratory therapy was
\end{abstract}

associated with age, current smoking status, number of respiratory drugs, number of daily respiratory drug doses and quality of life $(p<0.005)$. Adherence to respiratory therapy was not related to gender, GOLD stage, FEV ${ }_{1}$ or COPD medication costs. Conclusions: Adherence to COPD medication regimens is poor. Less frequent dosing regimens could be an effective method to enhance adherence to respiratory therapy. Quality-of-life monitoring within clinical practice settings could facilitate improved medication adherence.

Copyright $\odot 2011$ S. Karger AG, Basel

\section{Introduction}

Chronic obstructive pulmonary disease (COPD) is one of the leading causes of morbidity and mortality in industrialised and developing countries [1]. In 2020, COPD will likely become the third leading cause of death in the world [2]. The impact of COPD worldwide is expected to increase, resulting in a heavy economic burden [1]. The annual per capita health care expenditure on people with COPD is more than two times higher than on people without respiratory disease [3].

Suboptimal treatment adherence reduces the clinical benefit of the therapy and accounts for many of the observed differences between the efficacy (works under experimental conditions) and the real-world effectiveness

\section{KARGER}

Fax +4161306 1234

E-Mail karger@karger.ch

www.karger.com
(C) 2011 S. Karger AG, Basel

0025-7931/11/0824-0328\$38.00/0

Accessible online at:

www.karger.com/res
Tamas Agh

University Pharmacy Department of Pharmacy Administration

Semmelweis University, Hőgyes Endre Strasse 7-9

HU-1092 Budapest (Hungary)

Tel. +36 1216 1571, E-Mail aghtamas@t-email.hu 
of the drug treatment [4]. Although the average adherence rates in clinical trials have been estimated to be around $70-90 \%$ among COPD patients [5-7], in clinical practice, these rates are only in the range of $20-60 \%$ [810]. This reflects the fact that under real-life conditions, non-adherence to medication regimens poses a significant barrier to the optimal management of COPD patients. Discontinuation of medication may increase the frequency of exacerbations, the number of hospitalisations and the mortality rate [11-13]. Non-adherence to long-term therapies can result in poor health and increased health care costs [14].

Non-adherence is a multidimensional phenomenon; it frequently occurs for a variety of reasons. These include factors related to the characteristics of the patient, the disease, the therapies and also the doctor-patient relationship [14-16]. Factors influencing the medication adherence of COPD patients have not been thoroughly investigated [16-18]. It is necessary to identify factors related to adherence in order to develop more effective strategies that can improve medication-taking behaviour.

Adherence and health-related quality of life (HRQoL) are two important indicators for determining the success of drug treatments. Although HRQoL and medicationtaking behaviour have both been studied intensively, less is known about the association between these factors. Non-adherence does not have a clear negative impact on HRQoL. Non-adherence may improve HRQoL, for instance, when patients adapt their medication schedule to their own lifestyle, or it may decrease HRQoL because of increased morbidity or side effects [19]. Even less is known about the impact of HRQoL on medication adherence. Poor or good HRQoL may also be a trigger for medication discontinuation [19]. Therefore, identifying the dynamics between these two factors requires further analysis.

The objectives of this study were to estimate adherence to respiratory medication and to identify factors related to adherence in patients with different stages of COPD severity.

\section{Methods}

\section{Study Design}

This was an observational, cross-sectional study performed in Hungary. The study was approved by the Semmelweis University Regional and Institutional Committee of Science and Research Ethics.

The study was carried out in a Hungarian outpatient clinic. Four general practitioners and one pulmonologist participated in the study. Patients were referred by the participating physicians, and every patient who met the inclusion criteria and was born on an even day was enrolled in the study. The enrolment period was between March and November of 2009, and the planned number of subjects was 250 .

The subjects included in this study had been diagnosed with COPD at least 1 year prior to enrolment, were over 40 years of age and had received drug treatment. Patients were excluded if they had a history of asthma, allergic rhinitis, lung operation or other respiratory disease; a serious concomitant disease, such as serious heart failure or serious liver or renal failure; an acute coronary syndrome or acute cerebrovascular disease in the last 3 months, or if there had been any modification to their COPD drug treatment during the previous 3-month period.

All of the patients gave written consent to participate in the study after the details of the study had been described. For each patient enrolled in the study, the physician noted the age, gender, current smoking status and the currently prescribed respiratory therapy. The examination included post-bronchodilator spirometry and completion of a self-reported postal questionnaire. The questionnaire consisted of two parts, the Morisky Medication Adherence Scale (MMAS) and the EuroQol 5-dimension questionnaire (EQ-5D). The above-listed instruments were used with the prior authorisation of their authors. The monthly cost of the medication paid by each patient was calculated on the basis of the prescribed COPD therapy. The deadline for submission of the postal questionnaires was 31 January 2010.

\section{Medication Adherence}

The MMAS was used to evaluate medication adherence to respiratory therapy. The MMAS is a self-reported, well-validated instrument [20]. The scale consists of 4 items: forgetting, carelessness, stopping the drug when the patients feel better or stopping the drug because they believe it makes them feel worse. All of the questions on the scale referred only to the medication given for COPD. The scoring scheme of 'Yes' $=0$ and 'No' $=1$ was employed. The summary score of the MMAS ranges from 0 to 4 , in which higher scores indicate greater adherence. Patients scoring 3 or above were classified as 'adherent'.

\section{Quality of Life}

We used the self-reported EQ-5D to measure generic HRQoL. The scale consists of a 5-item descriptive system and assesses health in the 5 dimensions of mobility, self-care, activities, pain (discomfort and anxiety) and depression. Each attribute has 3 levels: no problems, some problems and major problems. Preferences for the scoring function were measured with the time trade-off technique [21]. EQ-5D scores range from 0 to 1 , in which higher scores represent a better HRQoL. The scale has good validity and reliability for COPD patients [22].

\section{Spirometry}

Spirometry was performed with Piston pulmonary function equipment. Fifteen minutes after inhalation of $400 \mu \mathrm{g}$ of powdered salbutamol, the forced expiratory volume in $1 \mathrm{~s}\left(\mathrm{FEV}_{1}\right)$ and $\mathrm{FEV}_{1} /$ forced volume vital capacity (FVC) was measured in all of the participants. COPD was defined according to the Global Initiative for Chronic Obstructive Lung Disease (GOLD) criteria for COPD [3]. To fulfill the GOLD guidelines, the post-bronchodilator $\mathrm{FEV}_{1} / \mathrm{FVC}$ has to be $<70 \%$. The GOLD classification of disease 
severity divides disease into stage I (mild COPD, with a predicted $\mathrm{FEV}_{1}<80 \%$ ), stage II (moderate COPD, with a predicted $\mathrm{FEV}_{1}$ between 50 and $80 \%$ ), stage III (severe COPD, with a predicted $\mathrm{FEV}_{1}$ between 30 and $50 \%$ ) and stage IV (very severe COPD, with a predicted $\mathrm{FEV}_{1}<30 \%$ ).

\section{COPD Medication Costs}

The cost of the COPD medication paid by the patient was calculated on a monthly basis. Drug prices were derived from the Hungarian drug formulary, Pharmindex [23]. Only long-term COPD drugs were included in the cost calculation. All costs were originally calculated in Hungarian forints (HUF). Costs displayed in euros (EUR) are based on the Hungarian National Bank's average exchange rate (in 2009).

\section{Statistical Analyses}

The statistical software SPSS Statistics 17.0 was used for the statistical analyses. Differences in the evaluated factors between adherent and non-adherent groups (adherent: MMAS total score 3-4; non-adherent: MMAS total score 0-2) were tested using Pearson's $\chi^{2}$ test for categorical variables or the Mann-Whitney U test for continuous variables. A logistic regression analysis was then performed using adherence as the dichotomous outcome variable to identify the independent predictors of non-adherence. Factors were entered in the model if they showed a significant univariate association with the studied variable. The level of significance was set to 0.05 .

\section{Results}

\section{General Characteristics of the Sample}

A total of 250 patients were asked to participate in the cross-sectional study described above. Of the 250 patients, 23 refused to participate. The remaining 227 patients were included at baseline. A total of 176 participants completed the study and sent back the self-reported postal questionnaire (77.5\% response rate). Of these responses, 170 were usable, as 6 had to be excluded because of one or more unanswered items.

There were more female (58.2\%) than male patients among the respondents. The mean age of the group was 63.83 years (SD 11.24). Three quarters of the patients were current smokers. The prevalence of GOLD stage II COPD was more than $50 \%$ in the study population. The mean number of daily respiratory drugs taken was 2.03 (SD 0.99 ), and the mean number of daily respiratory drug doses was 5.58 (SD 3.18). Patient characteristics and treatments are presented in table 1.

In total, $58.2 \%$ of the participants reported themselves to be adherent to respiratory therapy (table 2). Forgetting medication and 'feeling worse' from respiratory medication were found to be the most common causes of nonadherence.
Table 1. Main characteristics of the study population

\begin{tabular}{lc}
\hline Total sample & $170(100)$ \\
Gender & \\
$\quad$ Males & $71(41.8)$ \\
Females & $99(58.2)$ \\
Age & \\
40-50 years & $16(9.5)$ \\
$51-60$ years & $57(33.5)$ \\
$61-70$ years & $48(28.2)$ \\
$\geq 71$ years & $49(28.8)$ \\
GOLD stage & \\
I & $39(22.9)$ \\
II & $88(51.8)$ \\
III & $36(21.2)$ \\
IV & $7(4.1)$ \\
FEV 1 , \% & $64.21 \pm 17.34$ \\
EQ-5D score & $0.55 \pm 0.21$ \\
Current smokers & $124(72.9)$ \\
Main respiratory drug classes & \\
SABA & $54(31.8)$ \\
LABA & $15(8.8)$ \\
Combined LABA-inhaled corticosteroid & $52(30.6)$ \\
Long-acting anticholinergic & $69(40.6)$ \\
Short-acting anticholinergic & $22(12.9)$ \\
Combined anticholinergic-SABA & $56(32.9)$ \\
Inhaled corticosteroid & $15(8.8)$ \\
Oral theophylline & $62(36.5)$ \\
Number of daily drugs (respiratory indication) & \\
1 & $58(34.2)$ \\
2 & $65(38.2)$ \\
Number of daily drug doses (respiratory indication) & \\
$1-4$ & $72(42.3)$ \\
$5-8$ & $58(34.2)$ \\
Cost of COPD medication per month & $40(23.5)$ \\
paid by the patient, EUR & \\
\hline & $4.85 \pm 3.75$ \\
\hline
\end{tabular}

Values represent numbers of patients (percentage) or means \pm $\mathrm{SD}$, as appropriate. $\mathrm{SABA}=$ Short-acting $\beta$-agonist $\mathrm{LABA}=$ longacting $\beta$-agonist.

\section{Variables Associated with Medication Adherence Univariate Analyses}

In the first step, all collected variables were evaluated for their potential association with patient-reported adherence using Pearson's $\chi^{2}$ test or the Mann-Whitney U test (table 3). Adherence to respiratory therapy was related to age, HRQoL (EQ-5D score), current smoking status, number of daily respiratory drugs, number of daily respiratory drug doses and cost of COPD medication per month. No significant differences were observed between adherent and non-adherent patients with regard to gender, COPD severity (GOLD stage) and lung function $\left(\mathrm{FEV}_{1}\right)$. 
Table 2. Self-reported adherence to respiratory therapy

\begin{tabular}{lc}
\hline & $\mathrm{n}(\%)$ \\
\hline $\begin{array}{l}\text { Adherence rate } \\
\text { Adherent patients (MMAS score 3-4) }\end{array}$ & $99(58.2)$ \\
$\begin{array}{l}\text { Non-adherent patients (MMAS score 0-2) } \\
\text { MMAS score }\end{array}$ & $71(41.8)$ \\
0 & $5(2.9)$ \\
1 & $19(11.2)$ \\
2 & $47(27.6)$ \\
3 & $44(25.9)$ \\
4 & $55(32.4)$ \\
\hline $\begin{array}{l}\text { MMAS questions (yes response) } \\
\text { Do you ever forget to take your respiratory medicine? }\end{array}$ & $87(51.2)$ \\
$\begin{array}{l}\text { Do you ever have problems remembering to take } \\
\quad \text { your respiratory medicine? }\end{array}$ & $19(11.2)$ \\
When you feel better, do you sometimes stop taking & \\
$\quad$ your respiratory medicine? & $38(22.4)$ \\
Sometimes if you feel worse when you take your re- & \\
$\quad$ spiratory medicine, do you stop taking it? & $71(41.8)$ \\
\hline
\end{tabular}

Table 3. Comparison of adherent and non-adherent patients

\begin{tabular}{|c|c|c|c|}
\hline Variable & $\begin{array}{l}\text { Adherent } \\
(\mathrm{n}=99)\end{array}$ & $\begin{array}{l}\text { Non-adherent } \\
(\mathrm{n}=71)\end{array}$ & $\begin{array}{l}\mathrm{p} \\
\text { value }\end{array}$ \\
\hline \multicolumn{3}{|l|}{ Gender } & $0.671^{1}$ \\
\hline Males & $40(40.4)$ & $31(43.6)$ & \\
\hline Females & $59(60.6)$ & $40(56.4)$ & \\
\hline Age, years & $68.63 \pm 10.79$ & $57.14 \pm 8.00$ & $\leq 0.001^{2}$ \\
\hline \multicolumn{3}{|l|}{ GOLD stage } & $0.324^{1}$ \\
\hline I & $25(25.2)$ & $14(19.7)$ & \\
\hline II & $53(53.6)$ & $35(49.3)$ & \\
\hline III-IV & $21(21.2)$ & $22(31.0)$ & \\
\hline $\mathrm{FEV}_{1}, \%$ & $66.13 \pm 17.21$ & $61.54 \pm 17.28$ & $0.081^{2}$ \\
\hline Current smokers & $60(60.6)$ & $64(90.1)$ & $0.004^{1}$ \\
\hline \multicolumn{3}{|l|}{$\begin{array}{l}\text { Number of daily drugs } \\
\text { (respiratory indication) }\end{array}$} & $\leq 0.001^{1}$ \\
\hline 1 & $53(53.6)$ & $5(7.0)$ & \\
\hline 2 & $38(38.4)$ & $27(38.0)$ & \\
\hline 3 or more & $8(8.0)$ & $39(55.0)$ & \\
\hline \multicolumn{3}{|c|}{$\begin{array}{l}\text { Number of daily drug doses } \\
\text { (respiratory indication) }\end{array}$} & $\leq 0.001^{1}$ \\
\hline $1-4$ & $67(67.7)$ & $5(7.0)$ & \\
\hline $5-8$ & $26(26.2)$ & $32(45.0)$ & \\
\hline 9 or more & $6(6.1)$ & $34(48.0)$ & \\
\hline EQ-5D score & $0.50 \pm 0.24$ & $0.62 \pm 0.13$ & $0.001^{2}$ \\
\hline \multicolumn{4}{|l|}{$\begin{array}{l}\text { Cost of COPD } \\
\text { medication per month }\end{array}$} \\
\hline paid by patient, EUR & $3.18 \pm 2.63$ & $6.39 \pm 4.00$ & $\leq 0.001^{2}$ \\
\hline
\end{tabular}

Medication Adherence in COPD
Table 4. Independent predictors of adherence to respiratory therapy identified by multivariate logistic regression analysis

\begin{tabular}{lcc}
\hline Variable & Odds ratio (95\% CI) & p value \\
\hline Age & $1.081(1.011-1.156)$ & 0.023 \\
EQ-5D score & $0.011(0.000-0.594)$ & 0.027 \\
Cost of COPD medication per & & \\
month paid by patient & $0.906(0.727-1.130)$ & 0.382 \\
Currently smoking & $0.110(0.024-0.496)$ & 0.004 \\
Number of daily drugs (respiratory indication) & \\
$\quad 1$ & - & 1.00 \\
2 & $0.090(0.017-0.461)$ & 0.004 \\
3 or more & $0.050(0.004-0.669)$ & 0.024 \\
Number of daily drug doses (respiratory indication) & \\
$\quad-4$ & - & 1.00 \\
5-8 & $0.105(0.026-0.424)$ & 0.002 \\
9 or more & $0.019(0.003-0.118)$ & $\leq 0.001$ \\
\hline \multicolumn{2}{l}{ CI = Confidence interval. } \\
\hline
\end{tabular}

\section{Multivariate Analysis}

In table 4, the results of the logistic regression analysis are given, with age, HRQoL (EQ-5D score), current smoking status, number of daily respiratory drugs, number of daily respiratory drug doses and cost of COPD medication per month as independent variables. With the exception of the cost of COPD medication, all evaluated variables were found to be significantly associated with adherence. These variables together explained $71.2 \%$ of the variance of adherence (Nagelkerke $\mathrm{R}^{2}=0.712$ ).

\section{Discussion}

The present study indicates that the level of adherence to respiratory therapy is quite low. The adherence rate of $58.2 \%$ identified in this sample is consistent with the results of previous studies that evaluated self-reported adherence in COPD $[9,10]$. Understanding the factors associated with adherence to medication could help in enhancing health outcomes in COPD. In our study, adherence was associated with age, current smoking status, number of respiratory drugs, number of daily respiratory drug doses and HRQoL and was not related to gender, cost of COPD medication per month paid by the patient, GOLD stage or FEV . $_{1}$

In most prior studies, gender has not been found to be a predictor of medication adherence [18, 24, 25]. Group differences between the adherence levels of men and 
women reported in the literature may be caused by different predictors of adherence. One possible factor might be depression, as women with COPD tend to be more depressed than men [26].

Our results suggest that patients of advanced age are more adherent, which is consistent with previous findings $[5,18]$. Older patients are therefore more likely to adhere to therapy that requires adjustments in daily life.

The fact that a patient is a smoker seems to have a negative impact on adherence. A low adherence grade was observed in currently smoking patients, which is consistent with findings from previous studies $[18,26]$. The patient's perceptions of COPD and the understanding of their therapy are critical to adherence. Smokers with COPD should understand that their lung disease is associated with smoking. Consequently, patients who continue to smoke are expected to have lower adherence to drug treatment than those who quit.

We observed that the prescribed number of drugs and doses per day were inversely related to adherence. Treatment for COPD is based on the present health status of the patient. Patients with moderate to severe COPD are treated with combination therapy; therefore, in many cases, the number of drug substances cannot be reduced. As a partial result of the dosing frequency, a significant difference in adherence has been shown between the COPD drug classes [27-29]. Tiotropium, a once-daily inhaled drug, may enhance adherence compared with other inhaled respiratory medications that are dosed more times daily [27-29]. As our results indicate, it may be important to prescribe drugs with a fixed combination and/ or a low dosing frequency for the medication-based management of COPD in order to enhance adherence in routine clinical practice.

Despite the significant association between cost and adherence, the cost of COPD medication was not found to be a predictor of adherence in the logistic regression model. Our findings are inconsistent with the evidence provided by previous studies that have suggested that medication cost is one of the greatest barriers to achieving adequate adherence [30,31]. This discrepancy may be explained by the fact that COPD patients in Hungary pay only $10 \%$ (on average) of the respiratory drug cost, and the rest is reimbursed by the Hungarian Health Insurance Fund.

There were no significant differences between the adherent and the non-adherent groups with regard to COPD severity (GOLD stage) and lung function $\left(\mathrm{FEV}_{1}\right)$. Our results conflict with the findings of Turner et al. [18]. However, these conflicting results may be due to differences in the study populations. In the survey performed by Turner et al. [18], the mean post-bronchodilator $\mathrm{FEV}_{1}$ percentages (non-adherent group: $42.4 \% \pm 13.2 \%$; adherent group: $39.7 \% \pm 12.7 \%$ ) were lower than those found in our study (table 3). A higher burden of disease symptoms should make patients more adherent, whereas we found non-significant differences in adherence between GOLD stages. In fact, adherence might be more likely related to the patient's belief about how he or she is feeling than to the spirometry results. HRQoL is an indication of the patient's own perception of his or her health state. However, the correlation between HRQoL scores and $\mathrm{FEV}_{1}$ is too weak to enable prediction on the basis of the spirometry results of the effect of COPD on a patient's daily life [32].

The reported EQ-5D scores were negatively associated with adherence. Therefore, better HRQoL may be considered a trigger for non-adherence, which is consistent with the findings of Turner et al. [18]. In their study, Turner et al. [18] found significantly higher quality-of-life scores in the home and family section of the Recent Life Changes Questionnaire for non-adherent COPD patients. To understand our results, the possible reasons for non-adherence should be evaluated from the patient's point of view. The patient's decision regarding adherence is a personal trade-off between the efficacy of treatment and the negative effects (lifestyle changes, side effects) that it generates. A high level of adherence can improve the patient's HRQoL and reduce exacerbations but cannot fully reverse disease symptoms. However, COPD treatment regimens require adjustments to the activities of daily living; therefore, the interruption of drug therapy can also temporarily increase the patient's HRQoL. Drug treatment in newly diagnosed COPD patients might significantly improve HRQoL; however, the change in HRQoL might be much smaller in patients treated previously for longer durations [33]. Therefore, in the short-term, the improvement in the HRQoL should be greater than what would be expected from optimal adherence. From the patient's perspective, the benefits from the increase in HRQoL during the complication-free period outweigh the effects of the worsening disease symptoms. As for the decision regarding adherence, patients do not fully take the negative effects of their non-adherent behaviour into account.

Our study has some limitations. Measuring adherence with self-reporting methods tends to overestimate the actual adherence; however, there is not a gold standard for measuring adherence because each method has advantages and disadvantages. Future studies may use alternative methods for measuring adherence to verify our re- 
sults, including prescription monitoring, pill counting or electronic methods. We used postal administration to obtain more objective data because patients are normally intimidated by their physicians and tend to give the expected answers. However, postal administration of the MMAS and the EQ-5D has not been validated. These scales are designed for supervised self-administration to be sure that the questions are completed without the help of family or friends, who might influence the patient's opinion [34]. Our study used cross-sectional data, HRQoL and adherence to medication changes over time. A longitudinal study would provide more reliable data regarding the association between these variables.

In summary, non-adherence to medication regimens is a significant problem in the management of COPD.
Middle-aged and/or smoking patients should be given special attention by their physicians, as the non-adherence rate is high in these populations. Our findings suggest that using less frequent dosing regimens could be an effective method for enhancing adherence to respiratory therapy. Continuous HRQoL monitoring would aid in estimating the adherence of patients because patients may fail to take their medication when feeling well. This failure can lead to a higher HRQoL, which could be a predictor of non-adherence. Because of this non-adherent period, the patient's health status and consequently their long-term HRQoL will deteriorate. Therefore, HRQoL monitoring within routine clinical practice would aid in the improvement of medication adherence and health outcomes in COPD patients.

\section{References}

-1 Viegi G, Scognamiglio A, Baldacci S, Pistelli F, Carrozzi L: Epidemiology of chronic obstructive pulmonary disease (COPD). Respiration 2001;68:4-19.

-2 Holguin F, Folch E, Redd SC, Mannino DM: Comorbidity and mortality in COPD-related hospitalizations in the United States, 1979 to 2001. Chest 2005;128:2005-2011.

- 3 Rabe KF, Hurd S, Anzueto A, Barnes PJ, Buist SA, Calverley P, Fukuchi Y, Jenkins C, Rodriguez-Roisin R, van Weel C, Zielinski J: Global strategy for the diagnosis, management, and prevention of chronic obstructive pulmonary disease: GOLD executive summary. Am J Respir Crit Care Med 2007;176: 532-555.

4 Revicki DA, Frank L: Pharmacoeconomic evaluation in the real world: effectiveness versus efficacy studies. Pharmacoeconomics 1999;15:423-434.

5 Rand CS, Nides M, Cowles MK, Wise RA, Connett J: Long-term metered-dose inhaler adherence in a clinical trial. The Lung Health Study Research Group. Am J Respir Crit Care Med 1995;152:580-588.

6 Kesten S, Flanders J, Serby CW and Witek TJ: Compliance with tiotropium, a once daily dry powder inhaled bronchodilator, in one year COPD trials. Chest 2000;118:191S$192 \mathrm{~S}$.

7 van Grunsven PM, van Schayck CP, van Deuveren M, van Herwaarden CL, Akkermans RP, van Weel C: Compliance during long-term treatment with fluticasone propionate in subjects with early signs of asthma or chronic obstructive pulmonary disease (COPD): results of the Detection, Intervention, and Monitoring Program of COPD and Asthma (DIMCA) Study. J Asthma 2000;37: 225-234.
8 Krigsman K, Nilsson JL, Ring L: Refill adherence for patients with asthma and COPD: comparison of a pharmacy record database with manually collected repeat prescriptions. Pharmacoepidemiol Drug Saf 2007; 16:441-448.

9 Dolce JJ, Crisp C, Manzella B, Richards JM, Hardin JM, Bailey WC: Medication adherence patterns in chronic obstructive pulmonary disease. Chest 1991;99:837-841.

10 Bosley CM, Parry DT, Cochrane GM: Patient compliance with inhaled medication. Does combining beta agonists with corticosteroids improve compliance? Eur Respir J 1994;7:504-509.

11 Bourbeau J, Bartlett SJ: Patient adherence in COPD. Thorax 2008;63:831-838.

12 Regueiro CR, Hamel MB, Davis RB, Desbiens N, Connors AF Jr, Phillips RS: A comparison of generalist and pulmonologist care for patients hospitalized with severe chronic obstructive pulmonary disease: resource intensity, hospital costs, and survival. Am J Med 1998;105:366-372.

$\checkmark 13$ Osthoff M, Leuppi JD: Management of chronic obstructive pulmonary disease patients after hospitalization for acute exacerbation. Respiration 2010;79:255-261.

14 World Health Organization: Adherence to Long-Term Therapies: Evidence for Action. Geneva, World Health Organization, 2003, pp 1-45.

15 Baiardini I, Braido F, Bonini M, Compalati E, Canonica GW: Why do doctors and patients not follow guidelines? Curr Opin Allergy Clin Immunol 2009;9:228-233.
16 Restrepo RD, Alvarez MT, Wittnebel LD, Sorenson $\mathrm{H}$, Wettstein R, Vines DL, SikkemaOrtiz J, Gardner DD, Wilkins RL: Medication adherence issues in patients treated for COPD. Int J Chron Obstruct Pulmon Dis 2008;3:371-384.

17 Breekveldt-Postma NS, Gerrits CM, Lammers JW, Raaijmakers JA, Herings RM: Persistence with inhaled corticosteroid therapy in daily practice. Respir Med 2004;98:752759 .

18 Turner J, Wright E, Mendella L, Anthonisen $\mathrm{N}$ : Predictors of patient adherence to longterm home nebulizer therapy for COPD. Chest 1995;108:394-400.

19 Cleemput I, Kesteloot K, DeGeest S: A review of the literature on the economics of noncompliance. Room for methodological improvement. Health Policy 2002;59:65-94.

20 Morisky DE, Green LW, Levine DM: Concurrent and predictive validity of a self-reported measure of medication adherence. Med Care 1986;24:67-74.

21 Dolan P, Gudex C: Time preference, duration and health state valuations. Health Econ 1995;4:289-299.

-22 Rutten-van Molken MP, Oostenbrink JB, Tashkin DP, Burkhart D, Monz BU: Does quality of life of COPD patients as measured by the generic EuroQol five-dimension questionnaire differentiate between COPD severity stages? Chest 2006;130:1117-1128.

23 Pharmindex. Budapest, CMP Medica, 2009.

24 Corden ZM, Bosley CM, Rees PJ, Cochrane GM: Home nebulized therapy for patients with COPD: patient compliance with treatment and its relation to quality of life. Chest 1997;112:1278-1282. 
-25 Apter AJ, Reisine ST, Affleck G, Barrows E, ZuWallack RL: Adherence with twice-daily dosing of inhaled steroids. Socioeconomic and health-belief differences. Am J Respir Crit Care Med 1998;157:1810-1817.

26 Laforest L, Denis F, Van Ganse E, Ritleng C, Saussier C, Passante N, Devouassoux G, Chatte G, Freymond N, Pacheco Y: Correlates of adherence to respiratory drugs in COPD patients. Prim Care Respir J 2010;19: 148-154.

28 Jung E, Pickard AS, Salmon JW, Bartle B, Lee TA: Medication adherence and persistence in the last year of life in COPD patients. Respir Med 2009;103:525-534.

-29 Cramer JA, Bradley-Kennedy C, Scalera A: Treatment persistence and compliance with medications for chronic obstructive pulmonary disease. Can Respir J 2007;14:25-29.

30 Hughes CM: Medication non-adherence in the elderly: how big is the problem? Drugs Aging 2004;21:793-811.

-27 Breekveldt-Postma NS, Koerselman J, Erkens JA, Lammers JW, Herings RM: Enhanced persistence with tiotropium compared with other respiratory drugs in COPD. Respir Med 2007;101:1398-1405.
1 Soumerai SB, Ross-Degnan D, Avorn J, McLaughlin T, Choodnovskiy I: Effects of Medicaid drug-payment limits on admission to hospitals and nursing homes. N Engl J Med 1991;325:1072-1077.
2 Jones PW: Issues concerning health-related quality of life in COPD. Chest 1995;107: 187S-193S.

33 Cote I, Farris K, Feeny D: Is adherence to drug treatment correlated with health-related quality of life? Qual Life Res 2003;12:621633.

34 Santiveri C, Espinalt M, Diaz Carrasco FX, Marin A, Miguel E, Jones PW: Evaluation of male COPD patients' health status by proxies. Respir Med 2007;101:439-445. 